\title{
When Women are Equal: The Canada Research Chair Experience
}

\author{
Karen R. Grant \\ University of Manitoba \\ Janice Drakich \\ University of Windsor
}

\begin{abstract}
This paper focuses on the gendered nature of elite academic careers. Of interest is how similar or different the experiences are of women and men who have been appointed to Canada Research Chairs (CRCs). In particular, we examine the impacts of holding a CRC position and consider the factors that shape that experience for women and men. Based on interviews with 60 CRCs, we find that when women and men are given similar opportunities, their experiences are more alike than different. Where differences arise, these are often related to the experience of status/prestige associated with the CRC, and to family care responsibilities. Using expectation states theory, we demonstrate that when women are equal to men, the significance of gender as a determinant of the academic experience is diminished.

\section{RÉSUMÉ}

Cette étude se concentre sur l'influence du genre dans l'élite des carrières académiques. L'intérêt porte surtout sur le degré de similarité ou de différence entre les expériences des femmes et des hommes nommés à des postes de chaires de recherche du Canada (CRC). Nous examinons en particulier les répercussions sur les femmes et les hommes titulaires de CRC en tenant compte des facteurs qui forment l'expérience de ces individus. Nos entrevues avec 60 titulaires de CRC, nous mènent à conclure que les femmes et les hommes obtiennent des occasions similaires et que leurs expériences sont plus semblables que différentes. Lorsque des différences se présentent, elles sont plus souvent liées à l'expérience du statut et du prestige associés à la position de titulaire de CRC et à ses responsabilités familiales. En utilisant la théorie des états d'anticipation, nous démontrons que, lorsque les femmes sont égales aux hommes, la signification du genre en tant que déterminant de l'expérience académique est diminuée.
\end{abstract}


Over the last few decades, there has been sustained attention to the study of women in the academy. This body of research has, for example, focused on the underrepresentation of women in the professoriate (Ahmed, Denton, O'Connor, \& Zeytinoglu, 1999; CAUT, 2008; Dagg \& Thompson, 1988; Drakich, Smith, Stewart, Fox, \& Griffith, 1991; Drakich \& Stewart, 2006; Sussman \& Yssaad, 2005), the differential experiences of tenure and promotion (Acker, 2009; Ornstein, Stewart, \& Drakich, 2007; Stewart, Ornstein, Drakich, 2009), and the "leaky pipeline" (van Anders, 2004) that finds women leaving the academy at various points. Virtually all of this research has centred on the experiences of rank-and-file faculty members, and in some cases, the precarious experience of contingent workers in the academy (Webber, 2008). Very little research focuses on the elites of the academy.

Underlying much of the research is an assumption that universities have always been, and remain to a very large extent, "gendered" institutions. According to Currie and her associates, a gendered institution is one which is "dominated by masculine principles and structures that lead to advantages for male staff and disadvantages for female staff" (Currie, Thiele, \& Harris, 2002, p. 1). This has consequences for the ways in which academics carry out their work.

The research reported here focuses on the academic research careers of a sample of elite academics in Canada, those who hold Canada Research Chairs (CRCs). Of interest is how similar or different the experience is for women and for men who have been awarded CRCs. In particular, we focus on the impacts of holding a CRC and consider the factors that shape the experiences of women and men holding CRCs. We begin this paper with a brief description of the CRC program. We then outline the conceptual influences that inform our research, and provide details on our study design and methods. This is followed by the presentation of findings and analysis.

\section{THE CANADA RESEARCH CHAIRS PROGRAM: A BRIEF OVERVIEW}

When the CRC program was launched in 2000, the Canadian government committed $\$ 900$ million to fund 2,000 research chairs at universities and affiliated institutions. Billed as a key element "to help Canadian universities attract and retain the global research stars of today and recruit Canada's research stars of tomorrow" (Government of Canada, 2000), the CRC program was the mechanism to stop the outflow of Canadian talent to the competitive global marketplace for intellectual capital. The objectives of the CRC program are to strengthen research capacity in Canada by attracting and retaining high quality researchers, to train future generations of highly qualified personnel, and to improve Canada's capacity to advance knowledge in strategic areas of excellence at Canadian universities and affiliated institutions. (Additional program information is available on the CRC website at www.chairs.gc.ca.)

There are two types of CRCs. Tier 1 CRCs are awarded to senior, established researchers (defined by the program as "world leaders"), have a value of $\$ 200,000$ per year for a period of seven years, and are renewable. Tier 2 CRCs, awarded to "exceptional emerging researchers acknowledged by their peers as having the potential to lead in their field," in other words, "rising stars," have a value of $\$ 100,000$ per year for a period of five years and are renewable once. In addition to the financial allocation for the CRC, each university is provided with a Canada Foundation for Innovation (CFI) envelope to be used to fund infrastructure costs for all of the CRCs it has been allocated.

As of December 2010, a total of 1,848 CRCs have been awarded to researchers at 72 universities and affiliated institutions (see Table 1). Of these, $42.6 \%$ are Tier 1 and $57.4 \%$ are Tier 2. Women hold a total of 465 CRCs (or 25\%), while men hold 1,383 CRCs (or 75\%). More women hold CRCs in Social Sciences and Humanities Research Council (SSHRC) disciplines (nearly 38\%), while in Natural Sciences and Engineering Research Council (NSERC) and Canadian Institutes of Health Research (CIHR) disciplines, women constitute a much smaller minority of all CRCs in those fields $(18.6 \%$ and $25.6 \%$, respectively). More women than men hold Tier 2 compared to Tier 1 CRCs (31.3\% and 16.9\%, respectively). (C. Gervais, personal communication, December 15, 2010.)

While it is possible that some of the variations in the awarding of CRCs may be related to the nominal pool of eligible individuals in various fields (e.g., there are more women in social sciences and humanities disciplines, and there are fewer women in engineering and natural science disciplines), the nominal pool alone does not explain the differences noted. In the early days of the CRC program, universities simply did not nominate women. In 2000, only $14 \%$ of CRCs were awarded to women. In 
2002, the proportion of women receiving CRCs inched up to 19\% (Malatest \& Associates, 2004, p. 45). Ten years after the program was established, only one-quarter of the CRCs are now held by women (see www.chairs.gc.ca).

Table 1: Distribution of CRCs by Research Council, Tier, and Sex (as of December 2010)

\begin{tabular}{lcccccccc}
\hline & \multicolumn{2}{c}{ CIHR $(\mathrm{n}=611)$} & \multicolumn{2}{c}{ NSERC $(\mathrm{n}=838)$} & \multicolumn{2}{c}{ SSHRC $(\mathrm{n}=399)$} & \multicolumn{2}{c}{ TOTAL (n=1848) } \\
\hline & Male & Female & Male & Female & Male & Female & Male & Female \\
\cline { 2 - 9 } Tier 1 & 229 & 56 & 311 & 40 & 114 & 37 & 654 & 133 \\
Tier 2 & 225 & 101 & 371 & 116 & 133 & 115 & 729 & 332 \\
TOTAL & 454 & 157 & 682 & 156 & 247 & 152 & 1383 & 465 \\
\hline
\end{tabular}

Source: Carmen Gervais, Senior Program Officer, CRC Secretariat, personal communication, December 15, 2010.

The more recent increase in the number of women CRCs is related to several factors. In 2003, a group of women academics filed a human rights complaint against the CRC program and Industry Canada, the government department with oversight for the program. The human rights complaint alleged systemic discrimination against women under the Canadian Human Rights Code. The settlement of this complaint included a requirement that universities and affiliated institutions set goals and targets for the recruitment of women. (The human rights complaint is beyond the scope of this paper; for additional information, see Side \& Robbins, 2007.)

The representation of women in the CRC program remains a major concern within the academic community, but it was (and is) not the only area of concern. The social sciences and humanities community was deeply troubled at the small number of CRCs awarded to researchers who make up the majority of the university professoriate in Canada (Canadian Federation for the Humanities and Social Sciences, 2002). This structural design flaw in the program meant that this research community would not enjoy the significant infusion of resources that the CRC program would bring. It also laid the grounds for the underrepresentation of women in the CRCs simply because women are more commonly found in social science and humanities disciplines than they are in health sciences, natural sciences, and engineering disciplines.

\section{CONCEPTUAL INFLUENCES}

The CRC program highlights the critical role that it plays in the recruitment and retention of "world class" and leading researchers (Canada Research Chairs Program, 2008, p. 11). The academic elite segment of the professoriate has not generally been the subject of much research, and where it has been studied, the results clearly show that men are disproportionately represented. The first major investigation into academic elites was Harriet Zuckerman's research on the experience of Nobel laureates. She showed that elite scientists tended to be situated in western (mostly North American and European) countries, and they were disproportionately male. They enjoyed the benefit of "the accumulation of advantage." She says, "To the extent that these scientists are as competent as the rest or more so, they ultimately will do far better in terms of both role performance and rewards" (Zuckerman, 1977, p. 248).

Attempts to explain the underrepresentation of women in the academy have focused on systemic discrimination and the social processes of discrimination. Zuckerman and Cole (1975) and Merton (as cited in Zuckerman \& Cole, 1975) have stated that gender, an irrelevant characteristic in the evaluation of competence, does matter when there are ambiguous criteria by which to evaluate achievement. Four decades of research on the academic careers of women has pointed to the fact that gender matters in the evaluation of women's scholarship and career progress, and documents systemic discrimination (Fox, 2005; Kulis, Sicotte, \& Collins, 2002; Perna, 2005; Xie \& Shauman, 1998).

Zuckerman and Cole's (1975) observation of gender as an influencing characteristic has been explored systematically as a status characteristic in the theoretical research program expectation states theory (Berger, Conner, \& Fisek, 1974; Berger, Fisek, Norman, \& Zelditch, 1977). Expectation states 
theory provides us with a conceptual framework to understand the social processes of systemic discrimination.

According to expectation states theory, status characteristics shape the behaviour and evaluations of individuals in line with the characteristic's culturally biased expectations. A status characteristic is typically a personal or ascribed characteristic that is socially valued, differentially evaluated, and directly or indirectly associated with shared cultural beliefs about task performance and/or competency (e.g., gender or age). Expectation states theory posits that status characteristics are activated when they are diagnostic regardless of whether or not the characteristic is relevant to the situation. In other words, in the absence of objective criteria to assess ability, status characteristics are activated and expectations for performance follow their associated cultural beliefs and stereotypes. Consequently, gender is a status characteristic when cultural beliefs attribute greater merit, ability, and competence to men than to women. Strong empirical support for gender as a status characteristic and its influence on performance, evaluation, and decision making has been documented (Ridgeway, 2001). Ridgeway and Correll (2004, p. 684) argue that status characteristics "can create a web of subtle barriers to advancement in the workplace for workers who are in the lower status categories of these characteristics." This subtle web is the principal cause of the glass ceiling (Ridgeway, 2001). Of particular interest to us is the theory's suggestion that when unambiguous evaluation criteria are employed, the influence of gender is minimized or negated.

In the CRC nomination process, the activation of a status characteristic in the identification and evaluation of nominees is highly plausible and can explain, in part, the limited participation of women in the CRC program. Once the CRC is awarded, the recipient's elite academic status as a world-class researcher is unambiguous. Since little attention has been paid to the differences between women and men in the academic elite (Cole \& Zuckerman, 1984; Parker, Lortie, \& Allesina, 2010), the CRC program provides a unique opportunity to explore the question asked, but not answered, by Zuckerman and Cole in 1975 (p. 96): "When there is little question about competence in research, are men and women scientists by and large treated as equals?"

\section{OUR STUDY}

In 2004, we initiated a qualitative study of CRCs. We set out to explore the effects of the CRC program on the individual chairholders and on their institutions. In the interviews we conducted, we focused on three broad areas: (1) the impact of receiving a CRC on a faculty member's total academic role (teaching, research, and service/administration); (2) the impact of receiving a CRC on a faculty member's relationships with his/her department/faculty and colleagues; and (3) the responses of institutions to the CRC program, and in particular, to the individuals who have been awarded CRCs.

Interviews were conducted face-to-face (with only one exception in which the interview was conducted by teleconference), and generally lasted 1-1.5 hours. A semi-structured interview guide was used in the interviews. The topical outline included the following areas: the most significant impacts of the CRC; the level and kind of institutional support provided to the CRC; the extent to which the individual has control over the budget associated with the CRC; the effects of holding the CRC on the full academic role (i.e., teaching, research, and service/administration); the effects of holding the CRC on collegial relations, academic profile within the university and the discipline (nationally and internationally); interactions with other CRCs (at one's own university and nationally); and the pros and cons of holding the CRC. The renewal of the CRC was discussed in those cases where individuals were preparing for, or had already completed, the renewal process.

Our aim was not to have a sample that was representative in the statistical sense. Rather, we sought to include individuals from all three research councils, and both types of CRCs. We interviewed individuals at research-intensive universities, comprehensive universities, and primarily undergraduate universities. We report on 60 interviews completed between March 2004 and February 2007 in British Columbia, Alberta, Manitoba, Ontario, Quebec, and Nova Scotia. (We did not conduct interviews with CRCs at our own universities.)

In order to identify a sample, we focused on individuals who had held their CRC positions for a minimum of two years. This allowed time for the CRC holder to establish his/her research program and facilities. In total, we invited 131 individuals to participate in the study. The response to our invi- 
tation to participate in the study was very positive. While only 60 individuals (or $44.1 \%$ ) completed an interview, 39 (or 28.7\%) others wished to be interviewed but could not be accommodated due to scheduling difficulties. Thirty-seven individuals (or $27.2 \%$ ) did not reply to our invitation to participate in the study. Although who was interviewed was largely a function of individuals' availability, we would have liked to ensure the inclusion of members of designated groups in addition to women. However, the federal requirement of self-identification for visible minorities, aboriginal peoples, and persons with disabilities was a barrier to sample selection.

Table 2 provides a breakdown of the sample by research council, tier, and sex. A total of 29 women and 31 men were interviewed for this study. Although we attempted to interview equal numbers of CRCs across the three research councils, our sample ended up including an overrepresentation of researchers in the social sciences and humanities (30 or 50\% of the sample), and an underrepresentation of researchers in the health sciences ( 15 or $25 \%$ of the sample), and in science and engineering fields ( 15 or $25 \%$ of the sample).

Table 2: Sample by Research Council, Tier, and Sex

\begin{tabular}{lccccccc}
\hline TIER & \multicolumn{2}{c}{ CIHR } & \multicolumn{2}{c}{ NSERC } & \multicolumn{2}{c}{ SSHRC } & TOTAL \\
\hline & Male & Female & Male & Female & Male & Female & Total \\
Tyer 1 & 8 & 5 & 3 & 4 & 12 & 5 & $37(61.7 \%)$ \\
Tier 2 & 0 & 2 & 3 & 5 & 5 & 8 & $23(38.3 \%)$ \\
& 8 & 7 & 6 & 9 & 17 & 13 & 60 \\
\hline
\end{tabular}

More interviews were done with individuals holding Tier 1 than Tier 2 CRCs (37 or $61.7 \%$ as compared with 23 or $38.3 \%$ ). The overrepresentation of Tier 1 CRCs is explained by the fact that a disproportionate number of our early interviews were with Tier 1 CRCs. When we were unable to schedule interviews with a sufficient number of Tier 1 women CRCs, we shifted our sampling strategy to include Tier 2 CRCs, many more of whom were in SSHRC disciplines.

Each interview was transcribed verbatim. All transcripts were coded based upon an initial set of coding categories and subcategories derived from a review of the interview transcripts. Over several meetings of the investigators, the coding and analyses were cross-checked to ensure that we had been systematic and comprehensive in our approach to the data.

Although influenced by status characteristics theory, this research is not a formal "test" of the theory. Instead, as a qualitative study, our approach to data analysis was largely inductive in nature. We do a thematic analysis of the narrative accounts of the individuals in our study. In keeping with the practices related to the presentation of qualitative data we have included lengthy quotations from our interviews. These extracts provide a "thick" description (Geertz, 1994).

\section{UNDERSTANDING THE EXPERIENCE OF BEING AN ELITE RESEARCHER}

In another paper, we have developed a model to explain the experience of holding a CRC (Grant \& Drakich, 2010). Simply put, the relationship between the CRC and his/her institution is dialectical in that both affect each other, and are changed as a result of the CRC program. Holding a CRC provides to an individual a number of benefits, notably status/prestige (a symbolic reward), and time flexibility and access to resources (material rewards). As a consequence of these benefits, there are impacts on the CRC's research activities and relationships with colleagues, students, and programs. Inevitably, these impacts and outcomes feed into the institutional environment, and in some cases, the institutional practices at universities (e.g., profiling of CRCs, media attention, etc.).

This model was generated inductively to describe the experiences of the CRCs, individuals who are "elite" researchers within the academy. As elite researchers, the CRCs in our study recounted how they were transformed by holding the CRC. To illustrate, consider the following account of a Tier 1 SSHRC woman: 
Having a CRC, for the people whose work I know well, and who know my work well, made no difference. They knew who I was as a scholar and researcher anyway. But for the people, like one step removed, or for the types of programs that sort of pride themselves on bringing in people who already have some sort of credentials associated with their names, it opened up an enormous number of opportunities. And my younger son, who's a grad student in economics, said it's like this virtuous-circle thing, once you start getting one type of recognition, it [feeds] on itself. It gives you other types of recognition, whether you deserve them or not. And it's what the CRC program has certainly done for me.

This type of experience was fairly typical, although not universal, in our sample (Grant \& Drakich, 2010). Junior faculty ("rising stars") as well as senior faculty (established research leaders), and researchers across the disciplines recounted how they received accolades within their universities and their disciplines. They were able to secure significant funding for their research, their research programs became magnets for graduate students and post-doctoral fellows, their research opportunities were significantly enhanced, and their research output intensified often in unimaginable ways. One Tier 1 NSERC researcher used the notion of his research program becoming "bigger, faster, and stronger," and he concluded that the CRC allowed him "to do things that nobody has done before."

The question is whether the experiences of women and men CRCs are treated equally. Do they have similar or different experiences? We explore this in the following section.

\section{Comparing Women and Men as CRCs}

Women's and men's CRC experiences are very similar when it comes to time flexibility and access to resources. The critical differences are more evident in relation to status/prestige. In addition, the intersection of personal and professional lives (i.e., work/life balance) is very highly gendered and affects the ways women academics work.

The experience of status/prestige. By most indicators, the CRC program has resulted in the creation of an academic elite in Canadian higher education. A recent CRC report refers to the program as a critical mechanism for the recruitment and retention of "world-class scientists" and speaks of the CRCs as Canada's "top researchers." The program is seen as bringing "recognition and prestige to both the chairholder and the university" (CRC, 2008, p. 13).

In our interviews, we were told that CRCs have enjoyed an enormous amount of attention locally, nationally, and internationally. In the early days of the program, formal announcements of appointments were often hosted by the Prime Minister or other senior ministers in the federal government. Universities have showcased their CRCs in a number of ways, notably in their public relations efforts, and it was routinely reported by the individuals we interviewed that their universities used the CRC appointments to bolster research support in the CRCs' areas, and to build relationships in the community.

Both women and men enjoyed the conferring of status and prestige, but their experiences were often quite different. The differences are evident first in relation to the nomination process. It will be recalled that the majority of CRCs are men: 10 years after the program was established, only $25 \%$ of CRCs are held by women. Probably to some degree, the preponderance of men with CRCs is because men's place within the academy is never doubted. Such a view was indeed articulated by one of the Tier 2 SSHRC women we interviewed. She said:

I'm conscious of the issue of how many women we have [as CRCs]. I just wasn't at all confident I'd get it. People kept saying to me that you'll get it.... It's not that women were being disproportionately rejected; it's that they were being disproportionately not nominated.

Men's disproportionate representation among the CRCs reflects that they are more likely to work in fields that are well recognized and, importantly, that their credibility as researchers is seldom in dispute. Women, by contrast, are newer to the academy, and sometimes work in fields that are considered more "feminized" or less prestigious.

Several of the women we interviewed, but few of the men, spoke of how they felt that they and their area of research were somehow legitimated by virtue of their appointments as CRCs. For example, a Tier 1 CIHR woman told us that 
The main benefit has been that the kind of work that I do, some people don't consider real research because it's very applied. I think that having a CRC means "hey, that's legitimate research" and I think that's been the biggest payoff to me rather than opening doors for publications or anything like that.

The award of the CRC was a source of instant credibility for many. Women, especially, expressed views like the following from a Tier 2 SSHRC CRC:

I think in part, if you look internationally, if they happen upon you and then they see you are a Canada Research Chair, they automatically think, "oh, you must be good!" So it buys you instant credibility. I noticed that when I went to Australia in the fall. I think I had more credibility walking in the door than I would have if they hadn't seen my CV with it [CRC].

Finally, a woman who holds a Tier 2 NSERC CRC, but does interdisciplinary research, remarked:

Having it helps me psychologically, because it was a kind of recognition that has made it easier for me to speak up and be heard. It [recognition] had some impact on research, but more in how it made me feel-that I have support and can take risks. Feeling like I have the support of the people who are around me is huge.

We do not intend to suggest that only women were the beneficiaries of a "hierarchy of credibility" (Becker, 1967). Men, too, particularly those working in new areas of scholarship, enjoyed the reputational benefits that accrue from holding a CRC. Consider this account from a Tier 1 SSHRC man:

This has been an incredible expression of institutional support for, not so much a program of research but for the development of the field and a definition of a field which really in Canada had not been defined as an area of scholarly interest as such. I have felt myself to be at the centre of a new bringing together of people who have worked in diverse areas and now see how their research questions interplay with each other. And that's been tremendously exciting. And it feeds my work. It means that I have graduate students and I come in contact with scholars who are pushing me and opening up new theoretical areas.

The following two illustrations demonstrate the ways in which the CRC transformed the nature of the researchers' work, and served as a catalyst for the expansion and diversification of research opportunities and relationships:

I think that my status as a CRC does allow me to have some power within the institution, so that if I have an idea I can go and talk to my dean, or I can go and talk to the chair of the department and I can say, "well, why don't we do this, why don't we make this happen." I think it has given me the creative capacity to initiate different projects, a lecture series, or to bring people in. It allows me to imagine something new for the place where I work, and it has given me a kind of autonomy that I didn't have before and a profile within the institution that I didn't have before. It's a little bit of power. I think that there's an intellectual capital that's associated with having the research chair and that enables me to do things that I couldn't do before. (Tier 2 SSHRC woman)

These benefits are echoed in the statement from a Tier I CIHR man:

This has been the opportunity for me to do my best work. And it came at the right time. You get to a point in your career where what you are good for is actually helping to create a green house environment for other people, who are a bit younger, to do their best work. And without the CRC chair, I wouldn't have gotten the opportunity to do that. But that is what it has done. You see, it has created this opportunity, so that I can in a sense create this network around the province, a network of people...from a whole range of different places...finding ways to help them to do their best work, breaking down barriers...using the fact that I am quite prominent 
socially right now, to get people in the door...to do research that they otherwise wouldn't have been able to do at all. It's a much better fit for where I am in my own kind of career, than, you know, just being a principal investigator.

These two accounts actually demonstrate the critical differences between women's and men's experiences of status/prestige. For men, status/prestige are enhanced when the work they are doing is new, different, and perhaps on the margins. For women, the enhancement of status/prestige is more personal. It makes their place in the academy legitimate. It gives them credibility, as well as confidence, autonomy, and power.

The work experiences of CRCs. When it comes to the material aspects of the work life of CRCs, there are more similarities than differences between women and men. To some degree, this is because as elite researchers, the CRCs have "made it."

In the course of our interviews, we inquired about workload, and the division of time spent in the major areas of academic responsibility (teaching, research, and service/administration). What we quickly discovered is that CRCs work extraordinarily long hours. In an average week, both women and men CRCs spend 55 to 75 hours doing varied combinations of teaching, research, and service/administration. Both women and men indicated that their workload had increased dramatically since taking up the CRC. Particularly in the first year (and sometimes into the second year), individuals spent an inordinate amount of time setting up research space (especially when they had received infrastructure funding from the CFI). One of the most frequent complaints we heard was the increased amount of time spent on administration (of grants, primarily).

There is some evidence in the research literature that women are more often involved in mentoring and supporting students. For example, a survey of arts and science faculty at the University of Toronto found that women faculty, particularly in science disciplines, spent much more time informally advising students than did their male counterparts. Women science faculty also reported a higher level of involvement in advising and mentoring students than did their counterparts in the humanities (Grusec, Fox, Rice, Morgan, \& Diamond, 2000). We did not find significant differences with respect to the number of students supervised by CRCs. There are too many factors influencing the number of students such as available funding, available space, graduate student pools, types of graduate programs, etc. The variations in workload and the training of highly qualified personnel are better explained by other factors such as the size of the university, the granting council, the availability of financial resources to support graduate students, and the disciplinary culture.

Similar experiences were noted concerning the CRCs' access to resources. Both women and men reported that they generally had limited access to funds in the CRC award. Where differences were reported, they most commonly were connected with access to infrastructure (CFI) monies, but even here, the differences were not related to gender, but rather to discipline. SSHRC CRCs were much more likely to be encouraged not to apply for CFI infrastructure grants. In fact, several SSHRC CRCs reported that they were told that they were not "allowed" to apply for these grants. A Tier 1 SSHRC man said:

I was told I couldn't get it, and then wouldn't get it. I went to the website, read it, and said I don't get this. Not only that, but my colleague [another SSHRC CRC] who was away...had not applied. He'd been told the same thing. I made up applications here. I sent [them to] him over in [Europe]. We got them.

The same was true of a Tier 1 SSHRC woman who reported that at her university, internal (retention) SSHRC CRCs were not even informed of the possibility of applying to CFI. By discouraging SSHRC researchers from applying for CFI grants, universities were able to extend the funding envelope available to researchers in CIHR and NSERC disciplines, where it is believed that the infrastructure needs are greater and more costly. There is a long-held (and mostly mistaken) assumption that researchers in the social sciences and humanities have no need for infrastructure. As we found in talking with SSHRC researchers who had obtained CFI funding, the infrastructure has made a huge difference in their research programs, often being more important than the CRC itself!

Balancing academic work and family lives. Much has been written about balancing an academic career with family responsibilities and the disproportionate effect on women (Goulden, Mason, \& 
Wolfinger, 2004; Mason \& Goulden, 2002; Perna, 2005). It is not surprising that work/life balance is more of an issue for women CRCs than men CRCs. One woman's example of the differing context for her and her male colleagues echoes the now well-recognized landscape of gendered life in the academy:

I was a single parent for a long time trying to have an academic job and trying to balance everything. I think it's hugely difficult. It's a man's world. The roundtable I was on last night at 5:00 p.m. It went on until 8:00 p.m. It's all men. I was the only woman. I think some of them did have family responsibilities but they had partners who were taking care of the kids. But, you know, why have it at that time? There is never a consideration and what happens is you don't bring it up because it's a man's world. You want to be in the game. You want to be treated equally. This major collaborative research grant that I was on was a "dude project," and again, very few women [were on it]. Child care [and] the balance of family, it wasn't really talked about. It was just assumed that it was easy, that you could do it easily, and that you don't let the family interfere. (Tier 2 SSHRC woman)

Work/life balance affects most of the women with children regardless of the children's ages. A Tier 2 SSHRC woman with a teenage daughter who is somewhat independent but still requires attention, assistance, and supervision felt that she was expected to place her child "in storage" while she pursued her responsibilities related to networking and profile:

Put the kids in storage. I understand networking and I appreciate it. I don't mind meeting other researchers and trying to make links with universities. I'm connected to [a] community and I believe in collaboration. Part of it is you go to parties, or you go to openings, or you go to book launches, and that's important. But I can't actually do $90 \%$ of that because I want to be home at night. I don't get home until 7:00 every night. Again, [she's a] 14-year-old kid. She can't be alone every night. She needs a lot of [attention].

The effects of parental responsibilities are not limited to evenings and affect much more than networking and social events. CRCs are expected to attend national and international conferences, workshops, and meetings. In building a reputation and collaborative networks, participation in these external venues is essential. A Tier 1 NSERC woman explains the importance this way:

To be recognized as a very good researcher, it's not enough to publish. It's not enough to spend a lot of time with your students. Maybe things will change, but you still have to go around to organize in commercial confines, to be on some program committees, and it also helps you to get your papers accepted. Those things are very difficult. More difficult when you have a family and when you are a woman.

Consequently, women's absence from such activities may affect their productivity. A scholarly record that does not meet the standard of excellence associated with the CRC is likely to have negative implications in external evaluations of their record. The women CRCs recognize the conflict between their responsibilities to their children and to their positions. A Tier 1 NSERC woman explains her dilemma:

I feel that I should do more than my colleagues in research. Being a woman, it's difficult to do more than some of my [male] colleagues because I have two girls. I go to very few conferences. When I go away, I have to pay for someone to stay full-time at home and I can't get any reimbursement for that. It's [also] difficult for my children as they are too young for that now. The other thing is that when I get home I'm with them until [they go to bed] and they are asleep. That's not the case for my [male] colleagues around me. I have to leave at 5:00 or $5: 30$, but I'm spending less time than some of my colleagues who are doing research and also social relations.

This experience harkens back to the famous quotation by Charlotte Whitton (former mayor of Ottawa), who said: "Whatever women do they must do twice as well as men to be thought half as good." 
We did not observe gender differences in workload or time devoted to the position. However, women CRCs do care about their families and their positions and are fitting their work around their children's waking hours. Work/life balance is taking a significant toll on women CRCs with younger children, especially those who are single mothers.

Only a minority of men raised the issue of work/life balance, or the subject of their wives/partners and children. Even when their personal lives were mentioned, however, men did not describe how they had to juggle parenting responsibilities. By contrast, the women CRCs (particularly those with small children) had to figure out ways to work and to care for their children. A Tier 2 NSERC woman who had only just returned to work following a maternity leave described how she and her husband (also an academic) organized their work around childcare:

Typically [my husband] and I would put the kids to bed and we'd each do an hour, an hour and a half [of academic work]. It's not my best work. I'm just answering e-mail, things like that. Actually weekends are my most productive time. We hire a babysitter to come Sunday for three hours, and one of us will stay with the baby. The babysitter has the two-year-old, and one of us, we take turns, gets to come in to work. When I get three hours uninterrupted in my office on a Sunday, it's beautiful, the highlight of my whole week.

A Tier 2 SSHRC woman described how her ability to do her work as a CRC, including a significant amount of travel, was only made possible because her husband was more extensively involved in childcare. She said, "I'm not here day and night. I have a seven-year old. My partner only works part time, because you can't work [a full-time] schedule around somebody who's not home."

The conflict of when to have the baby-before or after tenure-is similarly felt with the CRC. A Tier 2 SSHRC woman was pregnant and related:

We've got kids, but they are older-they're 14 and 15. I'm having another one. We have to get help. That's just the reality of trying to do these high octane jobs and manage a family. It gave me pause about launching into another child.

In summary, women CRCs work as many hours as men, supervise as many students as men, and engage in service/administration to the same extent as men. Their experience as CRCs, however, is not the same. Women with children do not have the same freedom as men with children. Our interviews with women CRCs reflected their need to juggle and negotiate their work hours to accommodate their children's needs. In a gendered academic culture, this profile of a woman's academic life is not news. Rather, what is surprising is the absence of any mention of children and their care in the interviews we conducted with CRC men. The last 20 years has seen an increase (albeit small) in paternal involvement in childcare and a greater cultural shift in the expectation for shared parenting. It would appear that this shift has not had a significant impact on fathers who are academics. CRC men who are fathers continue to conduct research and build their careers unfettered by the childcare concerns that complicate the lives of women CRCs. Disappointingly, the architecture of the CRC program did not address the issue of work/life balance to provide women CRCs with a level playing field.

\section{DISCUSSION AND CONCLUSIONS}

We initiated our study of the CRCs to learn whether and how individuals' research careers are affected by being placed among Canada's academic elite. In the 10 years since the program was introduced, there is clear evidence that the CRCs are making a significant contribution to Canada's knowledge economy (CRC, 2008), and our research demonstrates that the personal and professional consequences for individual chairholders are, for the most part, very positive (Grant \& Drakich, 2010). In this paper, we have explored the gendered nature of the CRC experience in order to answer Zuckerman and Cole's question (1975, p. 96): "When there is little question about competence in research, are men and women scientists by and large treated as equals?"

Our interviews show quite clearly that women CRCs excel in much the same way as their male counterparts. Women and men are just as likely to describe their experiences as CRCs as transformative in nature. They generally describe how the CRC made it possible to engage in more substantial 
research programs, to include more students and trainees in their programs, and to be more productive. Both worked long hours and generally supervised many students.

Differences were apparent, however. Most notably, the status/prestige enjoyed by CRCs was experienced differently by women and men. Women more often reported a strong sense of personal validation as a result of being nominated for a CRC. Men, of course, felt honoured by the CRC nomination, but did not articulate that sense of honour as anything other than taken-for-granted. What was no big deal for men was typically a very big deal for women.

As well, our interviews uncovered the not surprising finding that women CRCs engage in their scholarly work while also carrying a more significant workload related to caregiving. Men in our sample reported having children, but never spoke of challenges related to juggling personal and professional responsibilities. Women, particularly those who were single parents, recounted the many ways in which they were burdened by childcare responsibilities, as well as the insensitivities of colleagues (e.g., collaborators, administrators, peer reviewers, etc.) to the multiple demands placed on women with children.

What our research suggests is that the award of the CRC is associated with a constellation of attributes and resources that unambiguously define the chairholder as a member of the academic elite. Having reached the pinnacle of the academic hierarchy effectively trumps gender as a key determinant of the faculty experience. In essence, women are equal. We are not saying that CRCs face no challenges or conflicts. We are saying that women CRCs have experiences more like those of their male counterparts - the good, the bad, and the ugly (Grant \& Drakich, 2010).

Among regular faculty, gender as a status characteristic is expressed by attributing greater competency and ability to men than to women. When women become members of the academic elite, the significance of gender diminishes.

\section{REFERENCES}

Acker, S. (2009). Gender equity and the tensions of tenure. Academic Matters, October/November. Retrieved from http://www.academicmatters.ca/current_issue.article.gk?catalog_item_ id=3408\&category=/issues/OCT2009

Ahmed, M., Denton, M., O'Connor, J., \& Zeytinoglu, I. (1999). Gender patterns in faculty participation: A decade of experience at a mid-sized university. Canadian Journal of Higher Education, 29(2), $1-32$.

Becker, H. S. (1967). Whose side are we on? Social Problems, 14(3), 239-247.

Berger, J., Conner, T. L., \& Fisek, M. H. (1974). Expectation states theory: A theoretical research program. Cambridge, MA: Winthrop.

Berger, J., Fisek, M. H., Norman, R. Z., \& Zelditch, M. (1977). Status characteristics and social interaction: An expectation-states approach. New York: Elsevier.

Canadian Association of University Teachers (CAUT). (2008). Narrowing the gender gap: Women academics in Canadian universities. CAUT Equity Review,2. Retrieved from http://www.caut.ca/uploads/EquityReview2-en.pdf

Canadian Federation for the Humanities and Social Sciences. (2002). Humanities, societies, cultures: Research and education in the 21st Century (A three-year plan for the Canadian Federation for the Humanities and Social Sciences). Ottawa: Canadian Federation for the Humanities and Social Sciences.

Cole, J. R., \& Zuckerman, H. (1984). The productivity puzzle: Persistence and change in patterns of publications of men and women scientists. Advances in Motivation and Achievement, 2, 217-258.

CRC (Canada Research Chairs Program). (2008). Canada Research Chairs: Year in review 20072008. Retrieved from http://www.chairs-chaires.gc.ca/about_us-a_notre_sujet/publications/07-08_ Year_in_review.pdf

Currie, J., Thiele, B., \& Harris, P. (2002). Gendered universities in globalized economies: Power, careers, and sacrifices. Lanham, MD: Lexington Books. 

OISE.

Dagg, A. I. \& Thompson, P. J. 1988. Miseducation: Women and Canadian universities. Toronto:

Drakich, J \& Stewart, P. (2007). Forty years later: How are university women doing? Academic Matters, 6-9. Retrieved from http://www.academicmatters.ca/AcademicMatters/docs/ AM\%20Feb\%202007\%20Issue.pdf

Drakich, J., Smith, D.E., Stewart, P., Fox, B., \& Griffith, A. (1991). Status of women in Ontario universities: Final report, volume 1: Overview. Toronto: Ministry of Colleges and Universities, Government of Ontario.

Fox, M. (2005). Gender, family characteristics, and publication productivity among scientists. Social Studies of Science, 35, 131-150.

Geertz, C. (1994). Thick Description: Toward an interpretive theory of culture. In L. Martin \& L. C. McIntyre (Eds.), Readings in the philosophy of social science (pp. 3-30). Cambridge, MA: MIT Press.

Goulden, M., Mason, M. A., \& Wolfinger, N. (2004). Do babies matter?: Redefining gender equity in the academy. Paper presented at the Mentoring for Academic Careers in Engineering: Proceedings of the PAESMEM/Stanford School of Engineering Workshop, Palo Alto, CA.

Government of Canada. (2000). Minister Manley appoints chair of Canada Research Chairs program's steering committee. Government of Canada. Retrieved from http://www.chairs.gc.ca/web/ media/releases/2000_april_e.asp

Grant, K. R., \& Drakich, J. (2010). The Canada Research Chairs program: The good, the bad, and the ugly. Higher Education, 59(1), 21-42.

Grusec, J., Fox, B., Rice, K., Morgan, K., \& Diamond, M. (2000). Arts and science survey. Toronto: University of Toronto Press.

Kulis, S., Sicotte, D., \& Collins, S. (2002). More than a pipeline problem: Labor supply constraints and gender stratification across academic science disciplines. Research in Higher Education, 43, 657-691.

Mason, M. A., \& Goulden, M. (2002). Do babies matter?: The effect of family formation on the lifelong careers of academic men and women. Academe, 88(6), 11-15.

Malatest \& Associates Ltd. (2004). Fifth-year evaluation of the Canada Research Chairs program: Final evaluation report. Retrieved from http://www.chairs-chaires.gc.ca/about_us-a_notre_sujet/ publications/fifth_year_review_e.pdf

Ornstein, M., Stewart, P., \& Drakich, J. (2007) Promotion at Canadian universities: The intersection of gender, discipline, and institution. Canadian Journal of Higher Education, 37(3), 1-25.

Parker, J. N., Lortie, C., \& Allesina, S. (2010). Characterizing a scientific elite: The social characteristics of the most highly cited scientists in environmental science and ecology. Scientometrics, 85(1), 129-143.

Perna, L. W. (2005). Sex differences in faculty tenure and promotion: The contribution of family ties. Research in Higher Education, 40, 277-307.

Ridgeway, C. (2001). Gender, status, and leadership. Journal of Social Issues, 57, 637-655.

Ridgeway, C., \& Correll, S. J., (2004). Motherhood as a status characteristic. Journal of Social Issues, 60, 683-700.

Side, K., \& Robbins, W, (2007). Institutionalizing inequalities in Canadian universities: The Canada Research Chairs program, NWSA, 19(3), 163-181.

Sussman, D., \& Yssaad, L. (2005). The rising profile of women academics. Perspectives, 6(2), 6-19.

Stewart, P., Ornstein, M., \& Drakich, J. (2009). Gender and promotion at Canadian universities. Canadian Review of Sociology, 46(1), 59-85.

van Anders, S. M. (2004). Why the academic pipeline leaks: Fewer men than women perceive barriers to becoming professors. Sex Roles, 51(9/10), 511-521. 
Webber, M. (2008). Miss Congeniality meets the new managerialism: Feminism, contingent labour, and the new university. The Canadian Journal of Higher Education, 38(3), 37-56.

Xie Y., \& Shauman, K. A. (1998). Sex differences in research productivity: New evidence about an old puzzle. American Sociological Review, 63, 847-870.

Zuckerman, H. (1977). Scientific elite: Nobel laureates in the United States. New York: The Free Press.

Zuckerman, H., \& Cole, J. R. (1975). Women in American science. Minerva, 13(1), 82-102.

\section{CONTACT INFORMATION}

Karen R. Grant

Vice-Provost (Academic Affairs)

University of Manitoba

208 Administration Building

Winnipeg, Canada

MB R3T 2N2

E-mail: karen_grant@umanitoba.ca

Karen R. Grant is a sociologist and the Vice-Provost (Academic Affairs) at the University of Manitoba. Her research interests focus on the sociology of women's health and sociological perspectives on the academy. She has conducted research on women's experiences with prenatal diagnosis, the impact of the 1997 Red River flood on women's health, women's caring work, and the impact of health care reform on women. She is conducting a study on obesity and health care. In her work on higher education, she has researched women in higher education administration, and the impact of the Canada Research Chairs program.

Janice Drakich is a sociologist at the University of Windsor. For more than 10 years, she served as the University's Director of Faculty Recruitment \& Retention. Her research examines issues relevant to academic women in Canadian universities-employment equity and promotion through the ranks; issues of fairness and equity in hiring procedures, and awards such as the Canadian Research Chairs initiative; and issues related to the future of universities in Canada, such as academic freedom, restructuring, and corporatization. Other research interests include child custody and divorce, fathers' rights groups, gender, and social psychology.

\section{NOTE}

This research was supported in part by grants from the University of Manitoba Research Grants Program and the University of Windsor Women's Research Grant Program. We would like to thank the Canada Research Chairs for their participation in our study. 